\title{
Letramento e suas dimensões
}

Eliane Nowinski da Rosa ${ }^{1}$

\begin{abstract}
Resumo
Uma vez que o letramento é proveniente de uma natureza dinâmica, variada e multidimensional, o presente artigo tem como meta discutir a relevância de letrar os aprendizes a partir de uma abordagem multidimensional, isto é, da inter-relação das suas quatro dimensões (linguística e sistemas de signos, cognitiva, sociocultural e desenvolvimental), as quais são utilizadas pelos leitores e escritores com o intuito de construir o sentido através da língua escrita. Para Stephen Kucer, ser letrado é ter a capacidade para negociar efetivamente e eficientemente essas quatro dimensões da língua escrita em determinadas situações.

Palavras-chave: Letramento; Dimensões; Ensino e Aprendizagem de Língua.
\end{abstract}

\section{Literacy and its dimensions}

\section{Abstract}

Since literacy comes from a dynamic, varied and multidimensional nature, this article aims to discuss the relevance of promoting learners' literacy from a multidimensional approach, that is, from the interrelationship of its four dimensions (linguistic and other sign systems, cognitive, sociocultural and developmental) which are used by readers and writers in order to construct meaning through written language. For Stephen Kucer, being literate is having the ability to negotiate effectively and efficiently these four dimensions of written language in certain situations.

Keywords: Literacy; Dimensions; Language Teaching and Learning.

\section{Introdução}

Ao longo das últimas décadas, em diversas partes do mundo, o interesse dos pesquisadores em estudar a natureza do letramento, juntamente com a criação de políticas de ensino voltados para a promoção de tal, tem aumentado significativamente.

No Brasil, inúmeros pesquisas e estudos têm sido realizados com o objetivo de aprimorar as práticas teórico-metodológicas adotadas para o desenvolvimento do letramento, assim como para tratar da elaboração e do aperfeiçoamento de políticas de ensino direcionadas aos diferentes níveis da educação (básico, fundamental, médio e superior). Dentre esses trabalhos, destacam-se: Altenhofen (2013), Bortolini (2009), Britto (2008), Broch (2014), Carvalho e Schlatter (2011), Corrêa (2010), Castro (2010), Fontes Monteiro (2006), Garcez e Schulz (2016), Goulart (2003, 2006), Jung (2002), Kleiman (1998, 2008), Morais (2009), Pinheiro (2006), Szundy (2017), entre outros.

\footnotetext{
${ }^{1}$ UNISINOS, São Leopoldo/RS; elianedr19@gmail.com. 
Durante muitos anos, no Brasil, mais precisamente entre fins do século XIX e a década de 1970, os debates referentes ao ensino de língua materna permaneceram restritos aos métodos de alfabetização e sua eficácia sem levar em consideração a aprendizagem da leitura e da escrita a partir de um viés sociocultural. Todavia, foi, em meados da década de 80 , que os estudiosos passaram a olhar o processo de aprendizagem da leitura e da escrita para além dos muros da escola, ou seja, passou-se atribuir à língua escrita o caráter de objeto social.

Uma vez que o conceito de alfabetização não era suficiente para abarcar as complexidades concernentes ao processo de aprendizagem da leitura e da escrita, foi necessário buscar uma ampliação através da adoção do termo letramento (oriundo do inglês literacy). As razões para tal residiram no fato de a sociedade brasileira estar centrada no uso da escrita e por a mesma exigir de seus usuários maneiras diversas de exercer as práticas sociais de leitura e escrita. Ademais, o crescente número de analfabetos, em território brasileiro, também suscitou discussões com o intuito de promover políticas de ensino voltadas para a erradicação do analfabetismo. Diante disso, a distinção entre alfabetização e letramento tornou-se inevitável. A alfabetização passou, então, a se restringir à aquisição do código escrito, enquanto o letramento foi introduzido para explicar e acompanhar o desenvolvimento social, econômico e cultural em nível nacional e internacional.

Por se tratar de um conceito amplo e complexo, desde a sua adoção na década de 80, o termo letramento vem apresentando muitas definições, ou melhor, notou-se uma incessante busca por uma definição ideal para o mesmo. Com os avanços das pesquisas ao longo dos anos, era natural esperar-se por reformulações e mudanças em seu conceito. Para Soares (2009), as dificuldades e impossibilidades de definição residem no fato de o letramento cobrir uma vasta gama de conhecimentos, habilidades, capacidades, valores, usos e funções sociais; logo, tornase difícil contemplar todas as sutilezas e complexidades envolvidas em seu conceito.

Nos dias atuais, dentre as definições mais importantes, destacam-se as da UNESCO (United Nations Educational, Scientific and Cultural Organization) ${ }^{2}$ e de Magda Soares, considerada a maior referência sobre alfabetização e letramento no Brasil. Segundo a UNESCO

\footnotetext{
${ }^{2}$ Agência especializada das Nações Unidas (ONU) com sede em Paris. Esta instituição, fundada em 4 de novembro de 1946, tem por objetivo contribuir para a paz e segurança no mundo mediante a educação, ciências naturais, ciências sociais/humanas e comunicação/informação. Para mais informações, acesse: <https://en.unesco.org/>.
} 
(2017, p. 14), o letramento é visto como a capacidade de identificar, compreender, interpretar, criar, comunicar e calcular, utilizando materiais impressos e escritos associados a diversos contextos. O letramento envolve um contínuo de aprendizagem que possibilita aos indivíduos alcançar seus objetivos, desenvolver seus conhecimentos e potenciais, assim como participar plenamente na comunidade e na sociedade como um todo. Conforme a referida instituição, esta definição envolve três características essenciais. Primeira, o letramento refere-se aos usos que os indivíduos fazem disso como um veículo de comunicação e expressão através de uma variedade de meios de comunicação. Segunda, o letramento é plural, porque é praticado em contextos particulares para fins particulares e usa linguagens específicas. Terceira, o letramento envolve um contínuo de aprendizagem que pode ser medido em diferentes níveis de proficiência. De acordo com a UNESCO (2017), a mudança da compreensão do letramento tem conduzido à evolução do modo como o letramento está organizado em relação às práticas e políticas de ensino. Em outras palavras, a evolução da noção de letramento tem contribuído para aprimorar o ensino e o uso da leitura e da escrita nos âmbitos escolar e social.

Para Soares (2004b, 2009), o termo letramento pode ser concebido como: a) o resultado da ação de ensinar ou de aprender a ler e escrever; b) o estado ou a condição que adquire um grupo social ou um indivíduo como consequência de ter-se apropriado da escrita; c) o desenvolvimento de comportamentos e habilidades de uso competente da leitura e da escrita em práticas sociais que envolvem a língua. Em linhas gerais, isto significa que o letramento compreende tanto a apropriação das técnicas para a alfabetização quanto o aspecto de convívio e o hábito de utilização da leitura e da escrita (SOARES, 2003, p. 3). Já que o letramento apresenta muitas facetas ou dimensões, torna-se imprescindível a adoção de múltiplas metodologias para promover e estimular a aprendizagem inicial da escrita (SOARES, 2004b). Com isso, verifica-se que a aprendizagem da leitura e da escrita está condicionada não só ao tipo de metodologia aplicada em sala de aula, mas também ao uso de tais habilidades como prática social.

Desse modo, levando em consideração a constatação de que o letramento tem evoluído de um processo linguístico a um ato cognitivo, e atualmente, para uma expressão sociocultural, o presente artigo tem como meta discutir a relevância da proposta de Stephen Kucer ${ }^{3}$

\footnotetext{
${ }^{3}$ Stephen Kucer, que é professor-doutor na Washington State University, atua na área de ensino de língua e educação. O referido professor também é membro da Reading Commission for the National Council of Teachers of English e faz
}

Periódico Horizontes - USF - Itatiba, SP - Brasil - e019033 
(Washington State University), que busca conceptualizar o letramento de um modo mais harmônico e holístico a partir da inter-relação de suas quatro dimensões (linguística e sistemas de signos, cognitiva, sociocultural e desenvolvimental). A escolha do tema deste artigo justificase por abordar um assunto ainda pouco explorado pelo meio acadêmico brasileiro até o presente momento, isto é, por apresentar o letramento sob uma perspectiva multidimensional e interdisciplinar, que pode fornecer uma base conceitual forte sobre a qual o currículo e o ensino podem estar fundamentados (KUCER, 2014).

\section{A origem do termo letramento}

O lexema "letramento" teve sua origem no termo inglês literacy que deriva da palavra literate (letrado) acrescida do morfema $-c y$ (= mento). Segundo Merriam-Webster's Collegiate Dictionary online ${ }^{4}$,

Literacy = é a qualidade ou o estado de ser letrado.

Literate = é ser capaz de ler e escrever; letrado, educado.

Conforme Oxford Advanced Learner's Dictionary online ${ }^{5}$, o item lexical literacy surgiu no final do século XIX a partir do termo literate. Este, por sua vez, é proveniente, no período do Inglês Médio, do latim litteratus (aprendido, letrado, erudito, etc.), o qual se originou de littera (letra do alfabeto).

Em território brasileiro, a palavra letramento foi introduzida, pela primeira vez, no meio acadêmico, pela linguista Mary Kato, em 1986, através de seu livro No mundo da escrita: uma perspectiva psicolinguística (SOARES, 2009). De acordo com Soares (2004b, p. 6),

[...] é em meados dos anos de 1980 que se dá, simultaneamente, a invenção do letramento no Brasil, do illettrisme, na França, da literacia, em Portugal, para nomear fenômenos distintos daquele denominado alfabetização, alphabétisation. Nos Estados Unidos e na Inglaterra, embora a palavra literacy

parte da equipe da Editorial Board of Reading Research Quarterly. Para mais informações, acesse <https://education.wsu.edu/skucer/>.

${ }^{4}$ Disponível em: https://www.merriam-webster.com/dictionary.

${ }^{5}$ Disponível em: https://www.oxfordlearnersdictionaries.com. 
já estivesse dicionarizada desde o final do século XIX, foi também nos anos de 1980 que o fenômeno que ela nomeia, distinto daquele que em língua inglesa se conhece como reading instruction, beginning literacy tornou-se foco de atenção e de discussão nas áreas da educação e da linguagem [...] segundo Barton (1994, p. 6), foi nos anos de 1980 que the new field of literacy studies has come into existence.

Assim, em visto da necessidade de reconhecer e de nomear práticas sociais de leitura e de escrita mais avançadas e complexas, e, mediante a constatação de que a população, mesmo que alfabetizada, não dominava as habilidades de leitura e de escrita necessárias à participação efetiva e competente nas práticas sociais e profissionais que envolviam a língua escrita, inúmeras discussões acabaram sendo desencadeadas para traçar uma distinção entre letramento e alfabetização. Além disso, a busca por soluções para o problema do analfabetismo, que estava e ainda continua ganhando grandes proporções, acabou se transformando em mais um dos motivadores para tais debates.

No que tange a essa distinção, pode-se dizer que alfabetização passou a ser definida como a aquisição do sistema convencional da escrita e letramento, como o desenvolvimento de comportamentos e habilidades de uso competente da leitura e da escrita em práticas sociais (SOARES, 2004a; 2004b). Todavia é importante destacar que esses são processos interdependentes, indissociáveis e simultâneos, porque a alfabetização se desenvolve "no contexto de" e "por meio de" práticas sociais de leitura e de escrita, ou seja, através de atividades de letramento, o qual somente pode se desenvolver "no contexto da" e "por meio da" aprendizagem das relações fonema-grafema, isto é, em dependência da alfabetização (SOARES, 2004a; 2004b). Consequentemente, pode-se dizer que há uma estreita relação entre os processos da alfabetização e do letramento.

Apesar do estabelecimento da noção de letramento por intermédio dessa distinção, percebe-se que o conceito de letramento continuou sofrendo ampliações e reformulações no decorrer dos últimos tempos. De acordo com a UNESCO (2004, p. 12), o modo como o letramento (literacy) é definido pode influenciar os objetivos e as estratégias adotadas, a criação de programas, assim como as metodologias de ensino e aprendizagem, os currículos e os materiais empregados. Segundo a instituição, a definição do termo também pode determinar como o progresso ou as conquistas na superação do analfabetismo são monitorados e avaliados. Isto é, 
como o desenvolvimento do processo de aprendizagem da leitura e da escrita está sujeito a sofrer interferências das políticas de ensino e das concepções teórico-metodológicas utilizadas pelos estudiosos e educadores. Por isso, é importante ter em mente que o letramento não se desenvolve somente a partir de uma única dimensão, mas da inter-relação de todas as suas dimensões, conforme afirmam Kucer $(2014,2015)$ e Kucer e Silva (2013).

\section{O letramento e suas dimensões}

De acordo com Kucer e Silva (2013), a maioria dos estudiosos tem focado seus interesses de pesquisa ou privilegiado apenas uma dimensão ou um viés da aprendizagem do letramento. Na visão do estudioso, isto pode, consequentemente, acarretar em uma visão de ensino que restringe e estreita o entendimento sobre o ensino e a aprendizagem do letramento por parte tanto do professor quanto do aluno.

Se é para o ensino e o aprendizado de alfabetização serem eficazes, é importante que mudemos de um bom conto para a sabedoria - para ver o todo. Tem sido estabelecido que a alfabetização é de natureza dinâmica e multidimensional (por exemplo, Bernhardt, 200; Gee, 1996; Kucer, 2009a; Luke 1995, 1998; New London Group, 1996). Tornar-se letrado - um processo sem fim - reflete aprender a gerenciar ou conciliar esses vários aspectos. [...] cada ato de uso do mundo real da língua escrita envolve quatro dimensões: linguística, cognitiva, sociocultural e desenvolvimental (KUCER; SILVA 2013, p. 4 , tradução nossa) ${ }^{6}$.

O letramento, na concepção de Kucer $(2014,2015)$ e Kucer e Silva (2013), apresenta quatro dimensões, as quais são denominadas de linguística e sistemas de signos, cognitiva, sociocultural e desenvolvimental. Estas, por sua vez, estão inter-relacionadas entre si e são utilizadas pelos leitores e escritores com o intuito de construir o sentido (meaning) por intermédio da língua escrita. Segundo o autor, essas dimensões do letramento, no entanto, operam em um modo transactivo e simbiótico (transactive and symbiotic manner), no qual cada

\footnotetext{
${ }^{6}$ If literacy teaching and learning are to be effective, it is important that we move from a fine tale to wisdom - to seeing the whole. It has been well established that literacy is dynamic and multidimensional in nature (e.g., Bernhardt, 200; Gee, 1996; Kucer, 2009a; Luke 1995, 1998; New London Group, 1996). Becoming literate - a neverending process - reflects learning to manage or juggle these various aspects. [...] every act of real-world use of written language involves four dimensions: linguistic, cognitive, sociocultural, and developmental" (KUCER; SILVA, 2013, p. 4).
}

Periódico Horizontes - USF - Itatiba, SP - Brasil - e019033 
uma influencia e é influenciada pelas demais.

Devido à expansão dos estudos a respeito do letramento em diversas áreas, surgiu uma nova tendência de compreender tal processo com base em novas perspectivas. Dessa forma, de acordo com Kucer (2014, p. 3, tradução nossa) $)^{7}$ :

Não surpreendentemente, há uma tendência de cada disciplina criar o letramento a sua própria imagem. Os linguistas enfatizam a dimensão linguística ou textual da leitura e da escrita. Os psicólogos cognitivos exploram os processos mentais que são usados para gerar significado através de e a partir do material impresso. Os socioculturalistas veem os atos de letramento como expressões de identidade do grupo que assinalam relações de poder. Os desenvolvimentalistas focam nas estratégias e mediações empregadas, e nos padrões exibidos, na aprendizagem da leitura e da escrita.

Vale mencionar que, historicamente, a interseção dos resultados dessas pesquisas tem contribuído significativamente para a área da educação e provocado grandes impactos no modo como os educadores definem, ensinam e avaliam o letramento no cenário escolar.

Se é para o letramento ser eficaz, é importante que os letramentos sejam concebidos como de natureza dinâmica, interconectada e multidimensional. Tornar-se ou ser letrado significa aprender efetivamente, eficientemente, e simultaneamente controlar os sistemas linguístico e de outros signos, as dimensões cognitiva, sociocultural e desenvolvimental da linguagem escrita de uma maneira transactiva. Na verdade, cada ato de uso do mundo real do letramento - ou seja, os eventos de letramento - envolve essas quatro dimensões (Kucer, 1991, 1994, 2008b; Kucer; Silva, 2013; Kucer; Silva; DelgadoLarocco, 1995) (KUCER, 2014, p. 4, tradução nossa).

Assim, com base em seus estudos e na reflexão dos trabalhos de Gee (2012), Luke (1995, 1998), e do New London Group (1996), Kucer (2014) estabeleceu as quatro dimensões do letramento, conforme exemplifica a Figura 1, a seguir:

\footnotetext{
${ }^{7}$ Not surprisingly, there has been a tendency for each discipline to create literacy in its own image. Linguists emphasize the language or textual dimension of reading and writing. Cognitive psychologists explore the mental processes that are used to generate meaning through and from print. Socioculturalists view acts of literacy as expressions of group identity that signal power relationships. Developmentalists focus on the strategies and mediations employed, and the patterns displayed, in the learning of reading and writing.

8 If literacy education is to be effective, it is important that literacies be conceived as dynamic, interconnected, and multidimensional in nature. Becoming or being literate means learning to effectively, efficiently, and simultaneously control the linguistic and other sign systems, cognitive, sociocultural, and developmental dimensions of written language in a transactive fashion. In a very real sense, every act of real-world use of literacy - that is, literacy events involves these four dimensions (Kucer, 1991, 1994; Kucer, Silva, \& Delgado-Larocco, 1995) (KUCER, 2014, p. 5).
}

Periódico Horizontes - USF - Itatiba, SP - Brasil - e019033 
Figura 1. As dimensões do Letramento

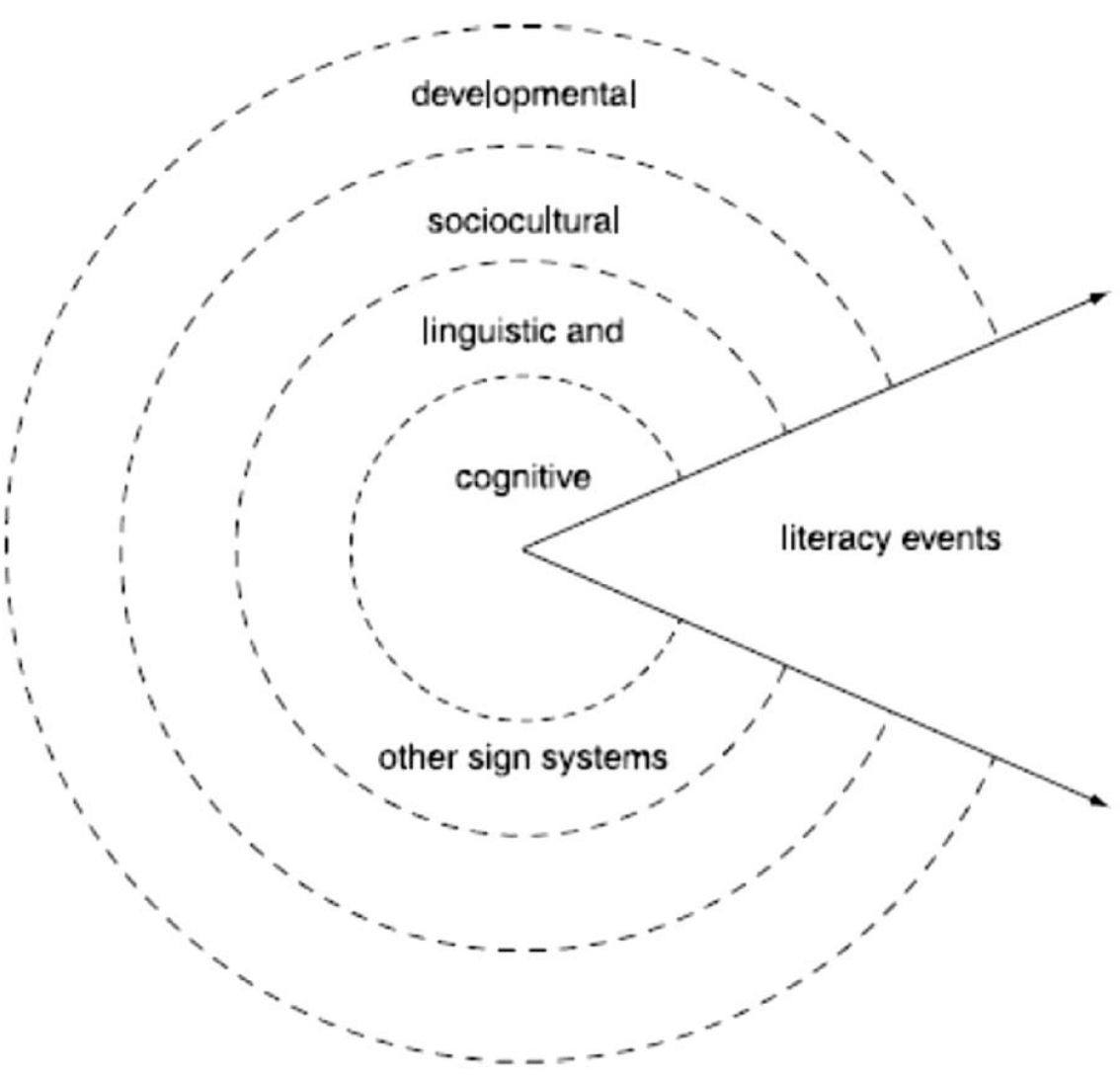

Fonte: KUCER, 2014, p. 5.

Segundo o autor, para entender o papel e o impacto do letramento na comunidade, na família e na sociedade, é preciso compreender a natureza do letramento em si, ou melhor, o que é o letramento e o que o letramento pode ou não ocasionar nos níveis social e individual.

Isso envolve ir além - mas não exclui - do papel de pronunciar, soletrar corretamente e ser gramatical. Tal movimento requer um exame do letramento através de uma variedade de lentes. Essas lentes nos permitem capturar a natureza variada, dinâmica e multidimensional da leitura e da escrita. É com base nesta natureza que a política pública, o financiamento e a educação deveriam ser fundamentados (KUCER, 2015, p. 1-2, tradução nossa).

As quatro dimensões representadas na Figura 1 tratam-se das lentes utilizadas para

${ }^{9}$ This involves moving beyond - but not excluding - the role of sounding out, spelling it right, and being grammatical. Such a move requires an examination of literacy through a variety of lenses. These lenses allow us to capture the varied, dynamic, and multidimensional nature of reading and writing. It is upon this nature that public policy, funding, and schooling should be grounded (KUCER, 2015, p. 1-2).

$$
\text { Periódico Horizontes - USF - Itatiba, SP - Brasil - e019033 }
$$


DOI: https://doi.org/10.24933/horizontes.v37i0.605

examinar o letramento. Por conseguinte, cada evento de letramento é concebido como envolvendo quatro dimensões: a linguística, cognitiva, sociocultural e desenvolvimental. Ser letrado significa, então, ter a capacidade para negociar efetivamente e eficientemente essas quatro dimensões da língua escrita em determinadas situações.

A dimensão linguística considera o indivíduo como "quebrador de código" ('code breaker') e "criador de código" ('code maker'); a cognitiva, como "criador do significado" ('meaning maker'); a sociocultural, como "usuário do texto" ('text user') e "crítico do texto" ('text critic'); ao passo que a desenvolvimental, como "cientista" ('scientist') e "trabalhador da construção" ('construction worker'). Conforme Kucer (2015, p. 2, tradução nossa) ${ }^{10}$, "os usuários do letramento fazem uso de todos esses quatro recursos de conhecimento quando engajados com qualquer evento da língua escrita".

Quanto à Figura 1, observa-se que, no centro do ato de letramento (literacy act), situa-se a dimensão cognitiva, cujo foco é nos processos e estratégias mentais utilizados para construir o significado (meaning).

Embora contestado por alguns (por exemplo, NICHD, 2000; Stanovich, 2000), muitos pesquisadores argumentam que a percepção de qualquer sistema particular da língua - por exemplo, letras, palavras, sintaxe - é afetada pelo contexto linguístico no qual o sistema está incrustrado (por exemplo, Cattell, 1885; Paulson \& Freeman, 2003; Rumelhart, 2004). Goodman $(1993,1996)$ e Smith (2004), entre outros, argumentam que os leitores seletivamente "escolhem" a partir da exibição gráfica. Nem toda a impressão disponível é processada; ao contrário, o cérebro seleciona apenas o que é necessário para a construção do significado. A informação perceptual não está limitada à imagem gráfica de uma determinada palavra. Os leitores também utilizam o ambiente sintático e semântico - ou seja, o contexto - dentro do qual qualquer palavra está inserida, assim como seu conhecimento prévio. A identificação da palavra é, portanto, afetada e facilitada pelos múltiplos recursos de informação, impressa e não impressa (KUCER, 2015, p. 10, tradução nossa) ${ }^{11}$.

\footnotetext{
${ }^{10}[. .$.$] literacy users draw upon all four of these knowledge sources when engaged with any written language event.$

${ }^{11}$ Although contested by some (e.g., NICHD, 2000; Stanovich, 2000), many researchers argue that the perception of any particular system of language - e.g., letters, words, syntax - is impacted by the linguistic context in which the system is embedded (e.g., Cattell, 1885; Paulson \& Freeman, 2003; Rumelhart, 2004). Goodman (1993, 1996) and Smith (2004), among others, have argued that readers selectively "pick" from the graphic display. Not all available print is processed; rather, the brain selects just that which is necessary for the construction of meaning. Perceptual information is not limited to the graphics of a particular word. Readers also utilize the syntactic and semantic environment - i.e., context - within which any word is embedded as well as their background knowledge. Word identification is therefore impacted and facilitated by multiple sources of information, print and nonprint (KUCER, 2015, p. 10).
} 
O processo da leitura tem como base a relação entre o leitor e o escritor. Kucer (2015) afirma que esse processo se desdobra dentro do ambiente que traz o leitor para o texto em primeiro plano; consequentemente, este contexto situacional dá origem ao evento do letramento, influencia o propósito do indivíduo com relação à leitura, e gera um impacto direto no modo como a impressão na página é exibida. Ao fundamentar-se nesta exibição, o leitor precisa empregar várias estratégias para construir o sentido do texto. Cabe ressaltar ainda que durante este processo de construção do entendimento do texto, o leitor monitora e avalia o sentido que está sendo construído (KUCER, 2015). Na visão de Kucer (2015, p. 13, tradução nossa) ${ }^{12}$, "a compreensão é construída ao estabelecer conexões, seja de texto para si, de texto para texto ou de texto para o mundo", ou seja, o sentido do texto, que antes era concebido como estático, agora é visto como oriundo de uma natureza dinâmica e variável.

Ademais, é interessante destacar que a dimensão cognitiva pode transcender as línguas, porque os usuários do letramento fazem uso de muitas estratégias e processos mentais compartilhados quando leem ou escrevem na primeira ou na segunda língua (DRESSLER; KAMIL, 2006; GENESEE; GEVA; DRESSLER; KAMIL, 2006; GOLDENBERG, 2010 apud KUCER, 2015). Independentemente do idioma, leitores e escritores criam e constroem ao invés de coletar significado.

Ao redor da dimensão cognitiva (ver em Figura 1) encontra-se a dimensão linguística e do sistema de signos, cujo foco é nos sistemas de comunicação (língua, arte, música, matemática, movimento) através dos quais o sentido pode ser transmitido. A dimensão linguística e do sistema de signos representa todos os entendimentos individuais sobre como a língua escrita funciona como um veículo para a comunicação.

O letramento, segundo Kucer (2015), depende de sistemas linguísticos como o grafofonêmico, a sintaxe, a semântica, a estrutura do texto e o gênero. Estes sistemas são governados por regras que determinam sua organização interna e a forma como eles interagem uns com os outros. Quanto ao conhecimento e domínio de determinados sistemas pelo indivíduo, aqueles estão sujeitos às experiências ou à falta delas com o letramento. Para o pesquisador, os usuários proficientes de uma determinada língua apresentam um entendimento

12 [...] comprehension is built on making connections, whether they are text-to-self, text-to-text, or text-to-world. Periódico Horizontes - USF - Itatiba, SP - Brasil - e019033 
bem desenvolvido de como os referidos sistemas operam e são considerados capazes de empregá-los para alcançar o sentido pretendido. Fora esses sistemas, os leitores e escritos também utilizam outros sistemas de signos, tais como: cor, som, imagem, movimento, entre outros; por isso o letramento é visto como um ato multimodal (multimodal act), que envolve vários sistemas de signos.

O leitor ou o escritor precisam coordenar esses sistemas transactivos com os significados cognitivos que estão sendo construídos. Os leitores e escritores, como quebrador de código e criador de código, empregam muitos sistemas multimodais diferentes ao invés de um único sistema ou modo para explorar e expressar significado (KUCER, 2015, p. 3, tradução nossa) ${ }^{13}$.

Já que os eventos de letramento são mais do que atos individuais de fazer uso da língua e de construir significado, o letramento em si também pode ser considerado como um ato social (social act). Esta afirmação baseia-se na constatação de que grupos diferentes usam o letramento de maneira diversificada para atingir propósitos variados. Logo,

[...] o significado e a língua são construídos e utilizados através do envolvimento em várias práticas de letramento são sempre estruturados pelas identidades sociais (por exemplo, étnica, cultural, de gênero) do indivíduo e do contexto social no qual operam. Leitores e escritores [...] engajam-se em multiletramentos e suas correspondentes práticas. Os significados gerados por meio desses letramentos e práticas representam perspectivas ao invés de verdades (KUCER, 2015, p. 3, tradução nossa) ${ }^{14}$.

Em torno da dimensão linguística (ver em Figura 1) está a dimensão sociocultural, cujo foco são as identidades sociais e a forma como os vários grupos usam o letramento para negociar e criticar suas relações com o mundo. Nessa dimensão, o letramento é percebido como um campo plural, múltiplo e diverso, por isso, a designação multiletramento (multiliteracy). Quanto à prática, esta também passa ser vista no plural, portanto, práticas de letramento. "Um exame sociocultural do letramento muda nossa atenção de textos, habilidades e indivíduos

\footnotetext{
${ }^{13}$ The reader or writer must coordinate these transacting systems with the cognitive meanings being constructed. Readers and writers as code breakers and code makers employ many different multimodal systems rather than a single system or mode to explore and express meaning (KUCER, 2015, p. 3).

${ }^{14}[\ldots]$ the meaning and language that are built and used through involvement in various literacy practices are always framed by the social identities (e.g., ethnic, cultural, gender) of the individual and the social context in which they operate. Readers and writers [...] engage in multiliteracies and their corresponding practices. The meanings generated through these literacies and practices represent perspectives rather than truths (KUCER, 2015, p. 3).
} 
DOI: https://doi.org/10.24933/horizontes.v37i0.605

descontextualizados para eventos, práticas e performances de letramento. O letramento tornase letramentos e o discurso torna-se d/Discursos (Gee, 1996, 1999)" (KUCER, 2014, p. 210, tradução nossa) $)^{15}$. Para a dimensão sociocultural, a leitura e a escrita não são apenas simples atos individuais do pensamento e da linguagem, mas também atos sociais padronizados e comportamentos de um certo grupo. O letramento não ocorre só porque um indivíduo possui ou aplica os processos e as estratégias linguísticas e cognitivas necessárias, mas porque os membros do grupo requisitam-nos (DEVINE, 1994 apud KUCER, 2014, p. 210).

Todavia, é relevante ressaltar que alguns defensores da visão sociocultural do letramento negam a existência das dimensões linguística e cognitiva. Segundo Kucer (2014, p. 210-211, tradução nossa) ${ }^{16}$ :

No que pode ser considerado, às vezes, como uma perspectiva um tanto reducionista, o grupo torna-se o principal, se não o assunto exclusivo de estudo [...] Embora o grupo seja poderoso por natureza, deve-se ter cuidado em não substituir uma compreensão limitada do letramento por outra. Vygotsky (1978) não refutou a noção de "mente", mas, ao contrário, conceptualizou a mente como sendo incorporada à sociedade. Da mesma forma, Purcell-Gates et al. (2004) considera "a atividade cognitiva como sendo moldada pelo e moldando o mundo social, e o mundo social como moldando e sendo moldado pelo cognitivo" (p. 88). Os grupos culturais são quebradores de código, criadores de código e criadores de significados, e as comunidades do discurso refletem os modos sociais de usar a língua (Nelson, 2008). Portanto, enquanto os eventos, práticas e performances de letramento podem variar de grupo para grupo, as dimensões linguística e cognitiva são parte integrante dessas variadas práticas de letramento.

Por conseguinte, não há como negar a existência de uma relação de influência recíproca entre o social, o cognitivo e o linguístico, ou melhor, da inter-relação entre as dimensões do letramento.

\footnotetext{
${ }^{15}$ A sociocultural examination of literacy shifts our attention from decontextualized text, skills, and individuals to literacy events, literacy practices, and literacy performances. Literacy becomes literacies and discourse becomes d/Discourses (Gee, 1996, 1999) (KUCER, 2014, p. 210).

${ }^{16}$ In what might be considered at times to be a rather reductionistic stance, the group becomes the primary if not the exclusive domain of study [...] Although the group is powerful in nature, care must be taken not to substitute one limited understanding of literacy for another. Vygotsky (1978) did not refute the notion of "mind," but rather conceptualized the mind as being embedded within society. Similarly, Purcell-Gates et al. (2004) view "cognitive activity being shaped by and shaping the social world, and the social world shaping and being shaped by the cognitive" (p. 88). Cultural groups are code breakers, code makers, and meaning makers and discourse communities reflect social ways of using language (Nelson, 2008). Therefore, while literacy events, practices, and performances may vary from group to group, the linguistic and cognitive dimensions are very much part and parcel of these varied literacy practices.
}

Periódico Horizontes - USF - Itatiba, SP - Brasil - e019033 
Ao redor da dimensão sociocultural (ver em Figura 1) situa-se a dimensão desenvolvimental, cujo foco é nas estratégias adotadas para construir um entendimento acerca das dimensões linguística, cognitiva e sociocultural. Isto quer dizer que o desenvolvimento retrata o crescimento da habilidade, no indivíduo, de envolver-se efetivamente e eficientemente com as demais dimensões a partir de uma variedade ampla de contextos. Vale relatar que tal envolvimento não se dá em estágios graduais e lineares, mas de forma simultânea e recíproca.

Na concepção da dimensão desenvolvimental, cada ato do letramento reflete os aspectos do letramento que o indivíduo consegue ou não controlar em um dado contexto. Neste caso, o desenvolvimento nunca acaba e o indivíduo se depara com eventos de letramento, os quais envolvem o uso do letramento em formas novas e diferentes. Conforme Kucer (2015, p. 4 tradução nossa) ${ }^{17}$ :

Estas experiências oferecem demonstrações, oportunidades e engajamentos para a aprendizagem do letramento, a qual resulta em avanços desenvolvimentais. Os leitores e escritores atuam como cientistas e trabalhadores quando eles constroem ativamente um entendimento em constante evolução dos letramentos e de suas práticas correspondentes. Tornar-se letrado, ao invés de ser letrado, descreve mais acuradamente nossa contínua relação com a língua escrita (Leu, 2000).

Dessa forma, pode-se dizer que a dimensão desenvolvimental está interessada na maneira como o aprendiz torna-se um quebrador e criador de código (breaker and code maker), criador de significado (meaning maker) e crítico e usuário de texto (text user and critic), pois "a criança descobre as regularidades abstratas da língua com base nos dados linguísticos disponíveis e na mediação fornecida" (KUCER; SILVA, 2013, p. 7, tradução nossa) ${ }^{18}$. Como o aprendiz está envolvido no processo de desenvolvimento, o mesmo experiencia e encontra os dados linguísticos expressos pelos demais usuários da língua alvo. Então, na tentativa de dar sentido a esses dados, o aprendiz formula hipóteses ou regras para alcançar a compreensão de como um

\footnotetext{
${ }^{17}$ These experiences offer demonstrations, opportunities, and engagements for literacy learning that results in developmental advancements. Readers and writers act as scientists and construction workers as they actively build an ever-evolving understanding of literacies and their corresponding practices. Becoming literate rather than being literate more accurately describes our ongoing relationship with written language (LEU, 2000).

${ }^{18}[. .$.$] the dimensions of language are actually constructed or built by the child through a process of induction. The child$ discovers the abstract regularities of the language based on the language data available and the mediation provided (KUCER; SILVA, 2013, p. 7).
}

Periódico Horizontes - USF - Itatiba, SP - Brasil - e019033 
determinado aspecto da estrutura da língua funciona. Ao utilizar tais hipóteses e regras como guia, o aprendiz envolve-se com o uso da língua e recebe retorno (feedback) dos outros usuários. Baseado no fornecimento deste último, tais hipóteses e regras podem sofrer modificações ou confirmações. Com isso, percebe-se que o aprendiz tem um papel ativo no desenvolvimento das dimensões do letramento, bem como não atua sozinho em tal desenvolvimento, pois os demais usuários da língua dão suporte para esse desenvolvimento por intermédio do fornecimento de dados linguísticos, retorno, e ambientes estruturados e previsíveis (KUCER, 2014). Estes esforços de ambas as partes são dirigidos pelo desejo de construir sentido, interagir e de comunicar com a comunidade. Isto demonstra que não é possível promover o letramento somente levando em conta apenas uma dimensão, mas com o apoio de todas. Para Kucer (2014, p. 291, tradução nossa) ${ }^{19}$ :

Um entendimento dessas dimensões é importante não só por razões acadêmicas ou intelectuais. Tal entendimento também pode servir como guia para a instrução do letramento. Os alunos precisam vir a comandar esses vários aspectos da leitura e da escrita, se quiserem ser usuários de letramento bemsucedidos em seus mundos. Do mesmo modo, as escolas devem apresentar e ensinar muitos desses vários aspectos, se quiserem que sejam desenvolvidos.

Assim, diante do que foi exposto nesta seção, verifica-se a importância de se olhar para o processo de letramento não só com base em uma faceta ou dimensão, mas a partir da interrelação de todas, pois tal perspectiva pode trazer contribuições significativas tanto para o meio acadêmico quanto para a elaboração e aperfeiçoamento de práticas teórico-metodológicas e de políticas de ensino. Embora dimensões como a linguística e a cognitiva não tenham recebido a merecida atenção por parte dos estudiosos, na atualidade, por considerarem apenas o viés social do letramento como o mais relevante, não há como negar a existência de uma influência mútua e recíproca entre as dimensões no desenvolvimento do processo de letramento por parte dos aprendizes. Visto que o letramento é proveniente de uma natureza dinâmica, variada e multidimensional (KUCER, 2014; 2015), é necessário que os currículos escolares e as políticas de ensino sejam elaborados a fim de estimular e promover o desenvolvimento do letramento

19 An understanding of these dimensions is important not just for academic or intellectual reasons. Such an understanding can also serve as a guide for literacy instruction. Learners must come to command these various aspects of reading and writing if they are to be successful literacy users in their worlds. Similarly schools must introduce and teach many of these various aspects if they are to be developed. 
apoiando-se na inter-relação das quatro dimensões do letramento para que, desse modo, a aprendizagem da língua seja bem sucedida.

\section{Considerações finais}

Com o passar dos anos, muitos estudos, ao redor do mundo, têm sido realizados com o intuito de investigar o letramento a partir de perspectivas e vieses variados. No entanto, é relevante destacar que, segundo Kucer e Silva (2013), a maioria desses estudos tem focado apenas em uma dimensão ou viés da aprendizagem do letramento. Já que o letramento é oriundo de uma natureza dinâmica, variada e multidimensional (KUCER, 2014; 2015), é relevante levar em consideração dois fatos. Primeiro, a necessidade de realizar mais pesquisas que visem a investigar as influências e as consequências que a inter-relação das dimensões pode exercer no processo de letramento, e, por fim, promover e estimular o desenvolvimento do processo de letramento através de práticas e políticas de ensino que contemplem a inter-relação entre essas quatro dimensões para, dessa forma, proporcionar uma aprendizagem da leitura e da escrita de maneira mais eficiente e efetiva nos âmbitos acadêmico e social.

Nesse sentido, ao levar em consideração o fato de que o letramento é composto por quatro dimensões (linguística, cognitiva, sociocultural e desenvolvimental), as quais encontramse interligadas e em mútua influência, o docente tem a possibilidade de abranger e aprimorar sua forma de "ensinar" o letramento no ambiente escolar, assim como preparar o aprendiz para ser capaz de compreender e usar tal conhecimento no dia a dia de forma a atender as exigências da sociedade, na qual está inserido.

\section{Referências}

ALTENHOFEN, C. V. Bases para uma política linguística das línguas minoritárias no Brasil. In: NICOLAIDES, C. et al. (orgs.). Política e políticas linguísticas. Campinas, SP: Pontes Editores, 2013, p. 93-116.

BORTOLINI, L. S. Letramento em uma escola de educação bilíngue na fronteira Uruguai/Brasil. 203 f. Dissertação (Mestrado em Letras) - Programa de Pós-Graduação em Letras, Universidade Federal do Rio Grande do Sul, Porto Alegre, 2009. 
BRITTO, L. P. L. Educação de adultos: formação x pragmatismo.REVEJ@ - Revista de Educação de Jovens Adultos, v. 2, n. 2, p. 53-60, 2008.

BROCH, I. K. Ações de promoção da pluralidade linguística em contextos escolares. 2014. 265 f. Tese (Doutorado em Letras) - Programa de Pós-Graduação em Letras, Universidade Federal do Rio Grande do Sul, Porto Alegre, 2014.

CARVALHO, S. C.; SCHLATTER, M. Ações de difusão internacional da língua portuguesa. Cadernos do IL, Porto Alegre, n. 42, p. 260-284, 2011.

CASTRO, F. da S. Letramento e alfabetização: sociogênese e/ou psicogênese, quais os caminhos da apropriação da escrita? 2010. 165 f. Dissertação (Mestrado em Educação), Pós- graduação em Educação, Pontifícia Universidade Católica do Rio Grande do Sul, Porto Alegre, 2010.

CORRÊA, P. M. O letramento do professor em formação inicial e o futuro professor como "agente de letramento". 2010. 137 f. Dissertação (Mestrado em Educação), Universidade Federal do Rio de Janeiro, Centro de Filosofia e Ciências Humanas, Faculdade de Educação, Rio de Janeiro, 2010.

FONTES MONTEIRO, T. R. Práticas de letramento e inclusão social: o caso de uma classe do ciclo II de educação de jovens e adultos. 2006. 148 f. Dissertação (Mestrado em Letras), Programa de Pós-Graduação em Letras, Pontifícia Universidade Católica do Rio de Janeiro, 2006.

GARCEZ, P. M.; SCHULZ, L. ReVEL na Escola: do que tratam as políticas linguísticas. ReVEL, v. 14, n. 26, p. 1-19, 2016.

GEE, J. Social linguistics and literacies: ideology and discourses. 4a ed. New York: Routledge/Taylor \& Francis, 2012.

GOULART, C. M. A. Uma abordagem bakhtiniana da noção de letramento: contribuições para a pesquisa e para a prática pedagógica. In: FREITAS, M. T.; SOUZA, S. J.; KRAMER, S. (orgs.). Ciências humanas e pesquisa: leituras de Mikhail Bakhtin. São Paulo: Cortez, 2003, p. 95-112.

Letramento e modos de ser letrado: discutindo a base teórico-metodológica de um estudo. Revista Brasileira de Educação, v. 11, n. 33, p. 450-460, 2006.

JUNG, N. M. A relação entre identidade de gênero, identidade étnico-linguística e as práticas de letramento em uma comunidade multilíngue no Brasil. In: II Simpósio Internacional de Bilinguismo, 2002, Vigo/Espanha. Actas/Proceedings // Simposio Internacional de Bilinguismo. Vigo/Espanha, v. 1, p. 1187-1206, 2002.

KATO, M. A. No mundo da escrita: uma perspectiva psicolinguística. Série Fundamentos. São Paulo: Ática, 1986. 
KLEIMAN, A. Ação e mudança na sala de aula: uma pesquisa sobre letramento e interação. In: ROJO, R. (org.). Alfabetização e letramento: perspectivas linguísticas. Campinas: Mercado de Letras, 1998, p. 173-203.

. Os estudos de letramento e a formação do professor de língua materna. Linguagem em (Dis)curso, v. 8, p. 519-541, 2008.

KUCER, Stephen B. Dimensions of literacy: a conceptual base for teaching reading and writing in school settings. 4aㅡ ed. New York: Routledge, 2014.

. Literacy: varied, dynamic, and multidimensional. Journal of Family Strengths, v. 15, Issue 2, p. 1-35, 2015.

KUCER, Stephen B.; SILVA, Cecilia. Teaching the dimensions of literacy. 2a ed. New York: Routledge, 2013.

LUKE, A. Getting over method: literacy teaching as work in "new times." Language Arts, 75(4), p. 305-313, 1998.

When basic skills and information processing just aren't enough: rethinking reading in new times. Teachers College Record, 97, p. 95-115, 1995.

MORAIS, G. A. S. Alfabetização na perspectiva do letramento: um estudo etnográfico. 2009. 154 f. Dissertação (Mestrado em Educação), Programa de Pós-Graduação em Educação, Universidade Federal do Piauí, Teresina, 2009.

New London Group. A pedagogy of multiliteracies: Designing social futures. Harvard Educational Review, 66, p. 60-92, 1996.

PINHEIRO, M. P. Letramento literário na escola: um estudo de práticas de leitura literária na formação da "comunidade de leitores". 2006. 306 f. Tese (Doutorado em Educação), Programa de Pós-Graduação em Educação, Universidade Federal de Minas Gerais, Belo Horizonte, 2006.

Reading the past, writing the future: fifty years of promoting literacy. Paris: United Nations Educational, Scientific and Cultural Organization, 2017. Disponível em: https://unesdoc.unesco.org/ark:/48223/pf0000247563. Acesso em: 01 dez. 2017.

SOARES, M. Alfabetização e letramento: caminhos e descaminhos. Revista Pátio, 2004a, p. 96 100.

. Letramento e alfabetização: as muitas facetas. Revista Brasileira de Educação, no 25, 2004b, p. 5-17.

Letramento: um tema em três gêneros. 3. ed. Belo Horizonte: Autêntica, 2009.

Periódico Horizontes - USF - Itatiba, SP - Brasil - e019033 
O que é letramento. Diário do Grande $A B C, 29$ de agosto de 2003, p. 3. Disponível em: http://www.verzeri.org.br/artigos/003.pdf. Acesso em: 01 dez. 2017.

SZUNDY, P. T. C. A base nacional comum curricular: implicações para a formação de professores/as de línguas(gens). In: MATEUS, E.; TONELLI, J. R. A. (orgs.). Diálogos (im)pertinentes entre formação de professores e aprendizagem de línguas. São Paulo: Blucher, 2017, p. 77-98.

The plurality of literacy and its implications for policies and programmes. Paris: United Nations Educational, Scientific and Cultural Organization, 2004. Disponível em:

https://unesdoc.unesco.org/ark:/48223/pf0000136246. Acesso em: 01 dez. 2017.

Recebido em janeiro de 2018.

Aprovado em janeiro de 2019. 